\title{
Epilepsy-associated Mutations in the Calcium-sensing Receptor Disrupt the Regulation of NALCN Sodium-leak Channel by Extracellular Calcium in Neurons
}

Chunlei Cang ${ }^{1,2}$, Boxun $\mathrm{Lu}^{1,3} \&$ Dejian Ren ${ }^{1, *}$

${ }^{1}$ Department of Biology, University of Pennsylvania, Philadelphia, PA 19104, U.S.A

${ }^{2}$ Present address: University of Science and Technology of China, Hefei, Anhui 230026, China ${ }^{3}$ Present address: State Key Laboratory of Medical Neurobiology and MOE Frontiers Center for Brain Science, School of Life Sciences, Fudan University, Shanghai 200433, China

\section{"To whom correspondence should be addressed:}

e-mail: dren@sas.upenn.edu 


\begin{abstract}
Most mammalian neurons have a resting membrane potential (RMP) of $\sim-50 \mathrm{mV}$ to $-70 \mathrm{mV}$, significantly above the equilibrium potential of $\mathrm{K}^{+}\left(\mathrm{E}_{\mathrm{K}}\right)$ of $\sim-90 \mathrm{mV}$. The resting $\mathrm{Na}^{+}$-leak conductance is a major mechanism by which neurons maintain their RMPs above $E_{K}$. In the hippocampal neurons, the TTX-insensitive, voltage-independent $\mathrm{Na}^{+}$leak is mediated by the NALCN cation channel. Extracellular $\mathrm{Ca}^{2+}\left(\mathrm{Ca}^{2+}\right)$ also controls the sizes of NALCN current $\left(\mathrm{I}_{\mathrm{NALCN}}\right)$ in a G-protein-dependent fashion. The molecular identities of the basal $\mathrm{Na}^{+}$ conductances and their regulation in other regions in the central nervous system and in the peripheral nervous system are less established. Here we show that neurons cultured from mouse cortices, ventral tegmental area, spinal cord and dorsal root ganglia all have a NALCN-dependent basal $\mathrm{Na}^{+}$-leak conductance that is absent in NALCN knockout mice. Like in hippocampal neurons, a decrease in $\left[\mathrm{Ca}^{2+}\right]_{\mathrm{e}}$ increases $\mathrm{I}_{\mathrm{NALCN}}$. Using shRNA knockdown, we show that the regulation of $\mathrm{I}_{\mathrm{NALCN}}$ by $\mathrm{Ca}^{2+}{ }_{\mathrm{e}}$ in neurons requires the $\mathrm{Ca}^{2+}$-sensing G-protein-coupled receptor CaSR. Surprisingly, the functional coupling from $\left[\mathrm{Ca}^{2+}\right]_{\mathrm{e}}$ to NALCN requires CaSR's distal C-terminal domain that is dispensable for the receptor's ability to couple $\left[\mathrm{Ca}^{2+}\right]_{\mathrm{e}}$ to its canonical signaling targets such as PLC and MAPK. In addition, several epilepsy-associated human CaSR mutations, though sparing the receptor's ability to sense $\mathrm{Ca}^{2+}$ e to maintain systemic $\left[\mathrm{Ca}^{2+}\right]$, disrupt the ability of $\mathrm{CaSR}$ to regulate NALCN. These findings uncover a unique mechanism by which CaSR regulates neuronal excitability via NALCN in the central and peripheral nervous system.
\end{abstract}




\section{Introduction}

Calcium regulates cellular processes ranging from muscle contraction, cell migration, hormone secretion, neurotransmitter release to gene expression ((Berridge et al., 2003; Clapham, 2007) for reviews). The cytosolic $\left[\mathrm{Ca}^{2+}\right]\left(\left[\mathrm{Ca}^{2+}\right]_{\mathrm{cyt}}\right)$ is tightly regulated, with the resting concentration to be $<100 \mathrm{nM}$. Increases in $\left[\mathrm{Ca}^{2+}\right]_{\text {cyt }}$ can be achieved by $\mathrm{Ca}^{2+}$ releases from intracellular $\mathrm{Ca}^{2+}$ stores such as endoplasmic reticulum and mitochondria, and/or by $\mathrm{Ca}^{2+}$ influx from the extracellular milieu. How intracellular $\mathrm{Ca}^{2+}$ serves as a "second messenger" to regulate the wide spectrum of physiological process has been extensively studied ((Berridge et al., 2003; Clapham, 2007) for reviews).

In contrast to that of intracellular $\mathrm{Ca}^{2+}$, how extracellular $\mathrm{Ca}^{2+}\left(\mathrm{Ca}^{2+}{ }_{\mathrm{e}}\right)$ signals to control cellular function is much less understood ((Brown et al., 1993; Hofer and Brown, 2003) for reviews). The systemic extracellular $\mathrm{Ca}^{2+}$ concentration $\left(\left[\mathrm{Ca}^{2+}\right]_{\mathrm{e}}\right)$ is generally regulated to be $\sim 1.2 \mathrm{mM}$ in mammals. However, the concentration in the brain can fluctuate significantly, particularly during extensive neuronal activities in regions where extracellular space is limited, and $\left[\mathrm{Ca}^{2+}\right]_{\mathrm{e}}$ can drop to as low as $0.1 \mathrm{mM}$ (Benninger et al., 1980; Heinemann and Pumain, 1980; Krnjevic et al., 1980; Nicholson et al., 1977; Pumain and Heinemann, 1985). Changes of $>0.2 \mathrm{mM}$ in cerebral cortex $\left[\mathrm{Ca}^{2+}\right]_{\mathrm{e}}$ have been observed between sleep and awake in cats and mice (Amzica et al., 2002; Ding et al., 2016). Large variations are also found under pathophysiological conditions such as hypocalcemia, hypoxia, ischemia, trauma and seizure (Brown and MacLeod, 2001; Heinemann et al., 1986; Morris and Trippenbach, 1993; Nilsson et al., 1993; Silver and Erecinska, 1990).

A key player in the maintenance of systemic $\mathrm{Ca}^{2+}$ levels is $\mathrm{CaSR}$, a $\mathrm{Ca}^{2+}$-sensing G-protein coupled receptor ((Brown et al., 1993; Hofer and Brown, 2003) for reviews). In the parathyroid glands, CaSR detects the systemic $\left[\mathrm{Ca}^{2+}\right]$ level and couples it to the secretion of parathyroid hormones (PTHs), which in turn regulate the balance among $\mathrm{Ca}^{2+}$ absorption/reabsorption through the gastrointestinal tract and the kidney, and $\mathrm{Ca}^{2+}$ absorption and releases in the bones ((Hebert and Brown, 1996) for a review). Both gain-of-function and loss-of-function CaSR mutations have been discovered and are implicated in the malregulation of systemic $\mathrm{Ca}^{2+}$ levels (Dershem et al., 2020; Pidasheva et al., 2004).

Intriguingly, CaSR is also widely expressed throughout the brain (Allen Brain Atlas), at high levels in the hippocampus and cerebellum (Ruat et al., 1995). The neuronal function of CaSR however is largely unknown (Riccardi and Kemp, 2012). In cultured mouse hippocampal 
neurons and sympathetic neurons, blocking CaSR inhibits dendritic growth (Vizard et al., 2008). At the nerve terminal and cell bodies, CaSR activation suppresses a nonselective cation channel, inhibits evoked synaptic transmission, and activates spontaneous neurotransmitter releases (Chen et al., 2010; Phillips et al., 2008; Smith et al., 2004; Vyleta and Smith, 2011; Xiong et al., 1997).

Human CaSR mutations have been implicated in epilepsy ((Riccardi and Kemp, 2012) for a review). Hypothetically, the epilepsy could be because of alteration in serum $\left[\mathrm{Ca}^{2+}\right]$ due to disruption in the PTH level, which leads to suppressing inhibitory neurons, activating excitatory neurons, or a more general effect on certain brain circuitry. Intriguingly, several reported CaSR mutations do not result in altered systemic PTH or serum $\mathrm{Ca}^{2+}$ level and yet are associated with seizure in affected individuals (Kapoor et al., 2008). How these mutations affect brain function is unknown. In this report, we found that the mutations disrupt CaSR's ability to regulate the $\mathrm{Na}^{+}$-leak channel NALCN in neurons.

NALCN is an $\sim 200 \mathrm{kDa}$ protein highly conserved among animals. It shares sequence and structural similarities with the pore-forming $\alpha$ subunits of voltage-gated $\mathrm{Ca}^{2+}(\mathrm{Cav})$ and $\mathrm{Na}^{+}$ ( $\mathrm{Na}_{\mathrm{V}}$ ) channels (Kang et al., 2020; Lee et al., 1999; Xie et al., 2020). The channel, as recorded in heterologous expression system and in neurons, is non-selective among cations and is largely voltage-independent (Eigenbrod et al., 2019; Funato et al., 2016; Hahn et al., 2020; Lee et al., 2019; Lu et al., 2007; Shi et al., 2016) (but see (Chua et al., 2020)). In mammalian brains, NALCN interacts with two large proteins UNC80 and UNC79, homologs of $C$. elegans proteins Unc-80 and Unc-79, respectively ((Ren, 2011) for a review). Affinity depletion of NALCN protein from brain lysates also depletes UNC79 and UNC80, suggesting the latter two are exclusively associated with NALCN and are auxiliary subunits of the NALCN complex (Wie et al., 2020). NALCN also associates with a smaller subunit NLF-1 (FAM155A) (Kschonsak et al., 2020; Xie et al., 2013). Mutations in humans and other animals in the complex result in developmental delay, hypotonia, epilepsy, lack of speech development, severe intellectual disability, breathing deficiency, disrupted circadian rhythm, altered sensitivity to anesthetics and premature death (Al-Sayed et al., 2013; Angius et al., 2018; Aoyagi et al., 2015; Bramswig et al., 2018; Campbell et al., 2018; Chong et al., 2015; Humphrey et al., 2007; Jospin et al., 2007; Koroglu et al., 2013; Kuptanon et al., 2019; Lear et al., 2013; Nash et al., 2002; Obeid et al., 2018; Perez et al., 2016; Pierce-Shimomura et al., 2008; Ren, 2011; Shamseldin et al., 2016; Stray-Pedersen et al., 2016; Takenouchi et al., 2018; Valkanas et al., 2016; Wie et al., 2020; Yeh et al., 2008). 
In cultured hippocampal neurons and midbrain dopaminergic neurons, we and others have previously shown that lowering $\left[\mathrm{Ca}^{2+}\right]_{\mathrm{e}}$ increases NALCN-mediated $\mathrm{Na}^{+}$leak channel current $\left(\mathrm{I}_{\mathrm{NALCN}}\right)$ and excites neurons (Lu et al., 2010; Philippart and Khaliq, 2018). This regulation of NALCN by $\mathrm{Ca}^{2+}$ e is G-protein-dependent and appears to involve CaSR, as CaSR agonists spermidine and neomycin suppresses the $\mathrm{Ca}^{2+}$ sensitivity of NALCN. NALCN is also regulated by other $\mathrm{G}_{\mathrm{i} / \mathrm{o}}$-coupled receptors (Philippart and Khaliq, 2018). Whether

CaSR-mediated NALCN regulation exists in other central nervous system (CNS) neurons and in peripheral neurons is unknown. In addition, the structural requirements on CaSR for the receptor's coupling of $\mathrm{Ca}^{2+}$ e to the channel is not established. In this study, we used shRNA knockdown to demonstrate that CaSR is required for the regulation of NALCN by $\mathrm{Ca}^{2+}{ }_{\mathrm{e}}$ in neurons. The ability to regulate NALCN by CaSR requires its $\mathrm{Ca}^{2+}$-sensing and, surprisingly, a domain in the C-terminus that is dispensable for the ability of the receptor to sense $\left[\mathrm{Ca}^{2+}\right]_{\mathrm{e}}$ and to couple it to other canonical targets. Finally, epilepsy-implicated mutations in this domain that do not lead to changes in the systemic $\left[\mathrm{Ca}^{2+}\right]$ levels nevertheless disrupt the receptor's ability to regulate NALCN, thus providing a novel mechanism by which the mutations cause epilepsy.

\section{RESULTS}

\section{NALCN mediates $\mathrm{Na}^{+}$leak in multiple brain regions and spinal cord}

We have previously recorded the TTX-insensitive background $\mathrm{Na}^{+}$leak currents (ILNA) from hippocampal neurons and found that $\mathrm{I}_{\mathrm{LNA}}$ is largely mediated by NALCN, as knocking out NALCN in the mice eliminated most of the current (Lu et al., 2007). To test whether other CNS neurons also have NALCN-dependent $\mathrm{I}_{\mathrm{LNA}}$, we measured $\mathrm{I}_{\mathrm{LNA}}$ in cultured mouse cortical, ventral tegmental area (VTA) and spinal cord neurons. Because of its small sizes, we measured $\mathrm{I}_{\mathrm{LNA}}$ by changes in the sizes of holding currents (at $-68 \mathrm{mV}$ ) upon a drop in extracellular $\left[\mathrm{Na}^{+}\right]$from $140 \mathrm{mM}$ to $14 \mathrm{mM}$ (with $126 \mathrm{mM} \mathrm{Na}^{+}$substituted by $\mathrm{NMDG}^{+}$, Figure 1A) (Lu et al., 2007). Similar to hippocampal neurons, all the types of CNS neurons cultured from wild-type (WT) mice have a non-inactivating background current I LNA (Figure $1 \mathrm{~A}, \mathrm{C})$. Such currents are largely absent in neurons cultured from the NALCN knockout (KO, $\mathrm{NALCN}^{-/}$, Figure 1B, C). These data, together with those from others (Flourakis et al., 2015; Ford et al., 2018; Lu et al., 2007; Lutas et al., 2016; Philippart and Khaliq, 2018; Shi et al., 2016; Yeh et al., 2017), suggest that NALCN-mediated basal $\mathrm{Na}^{+}$conductance is widely expressed in the CNS. The detection of ILNA is consistent with the wide expression of the NALCN gene as demonstrated by in-situ RNA staining in the brain ((Lu et al., 2007) and Allen Brain Atlas). 


\section{Extracellular $\mathrm{Ca}^{2+}$ regulates $\mathrm{NALCN}$-dependent $\mathrm{Na}^{+}$currents in cortical, VTA and spinal cord neurons}

In cultured hippocampal neurons, extracellular $\mathrm{Ca}^{2+}$ controls $\mathrm{I}_{\mathrm{LNA}}$, and such control provides a way for $\mathrm{Ca}^{2+}{ }_{\mathrm{e}}$ to regulate neuronal excitability (Lu et al., 2010). We tested whether $\mathrm{Ca}^{2+}$ e also regulates $\mathrm{I}_{\mathrm{LNA}}$ in other $\mathrm{CNS}$ neurons by recording the $\mathrm{Na}^{+}$-dependent current before and after $\left[\mathrm{Ca}^{2+}\right]_{\mathrm{e}}$ was reduced from $2 \mathrm{mM}$ to $0.1 \mathrm{mM}$ (Figure $2 \mathrm{~A}$ ). Similar to that in hippocampal neurons, lowering $\left[\mathrm{Ca}^{2+}\right]_{\mathrm{e}}$ induced a $\mathrm{Na}^{+}$-dependent inward currents in wild-type neurons cultured from cortices (Figure 2A, D), VTA (Figure 2B, D) and spinal cord (Figure 2C, D). Strikingly, such low $\left[\mathrm{Ca}^{2+}\right]_{\mathrm{e}}$-induced current $\left(\mathrm{I}_{\mathrm{LCA}}\right)$ was essentially absent in the $\mathrm{NALCN}^{-/-}$ neurons (see also (Philippart and Khaliq, 2018) for dopaminergic neurons). These data suggest that both $\mathrm{I}_{\mathrm{LNa}}$ and $\mathrm{I}_{\mathrm{LCA}}$ are mediated by NALCN in the CNS neurons.

\section{Extracellular $\mathrm{Ca}^{2+}$ regulates $\mathrm{NALCN}$-dependent $\mathrm{Na}^{+}$currents in peripheral neurons}

Like CNS neurons, peripheral neurons such as the dorsal root ganglion (DRG) neurons also have resting membrane potentials (RMPs) significantly depolarized to $E_{K}$. Persistent $\mathrm{Na}^{+}$ conductance resulting from the window-conductance of voltage-activated $\mathrm{Na}^{+}$channels Nav1.8 and Nav1.9 are present in the neurons (Herzog et al., 2001). However, DRG neurons in $\mathrm{Na}_{V} 1.8$ and $\mathrm{Na}_{v} 1.9$ knockout mice are not hyperpolarized compared to the WT (Priest et al., 2005), suggesting the presence of other subthreshold $\mathrm{Na}^{+}$conductance. To test whether NALCN contributes to the conductance, we compared $\mathrm{I}_{\mathrm{LNa}}$ between WT and $\mathrm{NALCN}^{-/-}$DRG neurons. WT DRG neurons had large TTX-resistant ILNA (Figure 3A, C). Such current was absent in the $\mathrm{NALCN}^{-/}$neurons. In WT, the current was also potentiated by lowering $\left[\mathrm{Ca}^{2+}\right] \mathrm{e}$, but such low $\left[\mathrm{Ca}^{2+}\right]_{\mathrm{e}}$-mediated current was largely absent in the $\mathrm{KO}$ (Figure 3B, D). Together, our data suggest that in both CNS and PNS neurons, NALCN contributes the basal $\mathrm{Na}^{+}$ conductance and it is regulated by $\mathrm{Ca}^{2+}{ }_{\mathrm{e}}$.

\section{CaSR is required for the $\mathrm{Ca}^{2+}$ sensitivity of NALCN}

How NALCN is sensitive to $\mathrm{Ca}^{2+}$ e is not well understood. $\mathrm{Ca}^{2+}{ }_{\mathrm{e}}$ inhibits cation channels such as Cavs and TRPs by blocking the channel pore (Owsianik et al., 2006; Yang et al., 1993). The $\mathrm{Ca}^{2+}$ sensitivity of neuronal NALCN under quasi-physiological conditions does not appear to involve such a pore-blocking mechanism (Lu et al., 2010). In hippocampal neurons, CaSR agonists spermidine and neomycin inhibit $\mathrm{I}_{\mathrm{LCA}}$, implicating CaSR in the regulation of NALCN (Lu et al., 2010; Xiong et al., 1997). To further test whether CaSR gene expression is required for NALCN's $\mathrm{Ca}^{2+}$ sensitivity in neurons, we designed an shRNA specifically against the mouse CaSR (mCaSR) gene (Figure 4A). In a heterologous expression system, the shRNA knocked down $\sim 90 \%$ of CaSR protein (Figure $4 \mathrm{~A}, \mathrm{~B}$ ). Transfection of the shRNA, but not a 
control with sequence mismatches, into cultured hippocampal neurons, eliminated $\mathrm{I}_{\mathrm{LCA}}$ (Figure 4C, D). These data suggest that CaSR gene expression is required for the $\mathrm{Ca}^{2+}$ sensitivity of NALCN in neurons.

\section{CaSR's $\mathrm{Ca}^{2+}$-sensing ability is required for its regulation of NALCN}

To define the structural requirements of CaSR in the regulation of NALCN in neurons, we developed a "knockdown-and-reconstitution" system where wild-type or mutant human CaSR (hCaSR) was transfected into mouse hippocampal neurons in which the endogenous mCaSR was depleted with a co-transfected shRNA specifically against mCaSR. HCaSR is highly similar to mCaSR at the amino acid level (93\% identity and $96 \%$ similarity), but differs from mCaSR at the nucleotide level. The target sequences of the shRNA designed against mCaSR do not match those of hCaSR (with 6 mismatches, Figure 4A). As such, the hCaSR used for transfection is resistant to the mCaSR-specific shRNA. Transfecting wild-type hCaSR completely restored $\mathrm{I}_{\mathrm{LCA}}$ in the mCaSR-knocked down neurons (Figure 4C, Figure 5A, C).

CaSR detects changes in $\left[\mathrm{Ca}^{2+}\right]_{\mathrm{e}}$ through conformational changes upon ligand-binding to its extracellular ligand binding domain, and transduces the signal to intracellular targets such as phospholipase C (PLC) and protein kinases ((Brown et al., 1993; Hofer and Brown, 2003) for reviews). An hCaSR bearing a hyperparathyroidism- and hypercalcemia- associated point mutation R185Q in the receptor's extracellular domain is unable to sense $\left[\mathrm{Ca}^{2+}\right]_{\mathrm{e}}$ (Bai et al., 1997). In contrast to the WT hCaSR, the R185Q mutant was unable to restore $\left[\mathrm{Ca}^{2+}\right]_{\mathrm{e}}$-sensitive $\mathrm{I}_{\mathrm{NALCN}}$ in neurons in which the endogenous $\mathrm{mCaSR}$ was knocked down (Figure 5B, C).

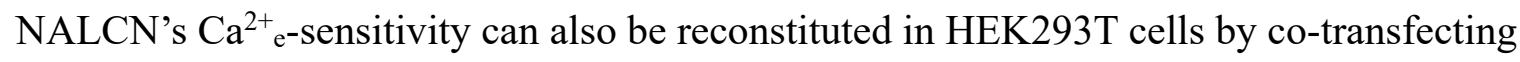
CaSR, Src529 (a constitutively active Src mutant) and UNC80 (Lu et al., 2009; Stray-Pedersen et al., 2016). In contrast to WT, the R185Q mutant was unable to reconstitute NALCN's $\mathrm{Ca}^{2+}$ sensitivity (Figure 5D-F). These data suggest that CaSR's ability to sense $\mathrm{Ca}^{2+}$ is required for the coupling of changes in $\left[\mathrm{Ca}^{2+}\right]_{0}$ to NALCN by the receptor.

\section{CaSR's C-terminus, which is dispensable for $\mathrm{Ca}^{2+}$-sensing, is required for the NALCN regulation}

We further tested whether the ability of CaSR to couple $\mathrm{Ca}^{2+}{ }_{\mathrm{e}}$ to its known intracellular targets is sufficient to couple $\mathrm{Ca}^{2+}{ }_{\mathrm{e}}$ to NALCN. CaSR contains a large intracellular C-terminus, 216 residues in the human isoform. The $\mathrm{C}$-terminus is highly conserved among mammals (Figure $6 \mathrm{~A}$ ), but its function is not well established. Compared to the wild-type (WT), hCaSR mutants 
lacking as large as 190 amino acids in the C-terminus (deletion after T888) have apparently equal or better ability for surface expression, receptor dimerization, $\mathrm{Ca}^{2+}$ sensing, stimulation of IP3 production and activation of the MAPK pathway (Bai et al., 1998; Chang et al., 2001; Gama and Breitwieser, 1998; Ray et al., 1997; Zhang and Breitwieser, 2005; Zhuang et al., 2012), which are some of the most well characterized cellular functions of CaSR.

Remarkably, hCaSR truncated at T888 (CaSR1-888) almost completely lacked the ability to confer NALCN's $\mathrm{Ca}^{2+}$ sensitivity in neurons (Figure 6C). Additional truncational mutants suggest that CaSR retains its ability to regulate NALCN in neurons when containing amino acids $1-1010$ or 1-1077, but the ability is significantly reduced when CaSR is truncated to amino acid 895 or 980 (Figure 6B, C).

We further tested the importance of CaSR's C-terminus in heterologous expression system. Similar to those tested in neurons using the knockdown-and-reconstitution system, the $\mathrm{Ca}^{2+}$-sensitivity of NALCN currents (represented as the ratio of current amplitudes measured under 1.2 and $\left.0.1 \mathrm{mM}\left[\mathrm{Ca}^{2+}\right]_{\mathrm{e}}, \mathrm{I}_{1.2 \mathrm{Ca}} / \mathrm{I}_{0.1 \mathrm{Ca}}\right)$ remained apparently intact in cells co-expressing hCaSR with the C-terminus deleted up to amino acid 1010, but was largely diminished when hCaSR was further truncated to amino acid 980 (Figure 6D, E). These results suggest that the C-terminal region of aa 888-1010 plays an essential role in regulating NALCN. CaSR without this region, though able to sense $\mathrm{Ca}^{2+}$ e and to couple it to other known signaling cascades such as the generation of IP3 and the activation of MAPK, is unable to couple $\mathrm{Ca}^{2+}{ }_{\mathrm{e}}$ to NALCN,

\section{Epilepsy-implicated CaSR mutations disrupt the receptor's ability to regulate NALCN}

Given the differential requirements of CaSR's C-terminus in the receptor's ability to couple $\mathrm{Ca}^{2+}$ e to NALCN and that to the other targets such as PLC and MAPK, we searched human CaSR mutations that might specifically affect the receptor's coupling to a subset of targets. Many human CaSR mutations are implicated in epilepsy, but the underlying mechanisms are not well understood (Pidasheva et al., 2004). We tested a panel of CaSR mutations (E354A, R898Q and A988V) found in epileptic patients who do not have abnormal systemic $\mathrm{Ca}^{2+}$ or PTH levels (Kapoor et al., 2008). The apparent normal levels of serum $\left[\mathrm{Ca}^{2+}\right]$ indicate normal functional coupling by the CaSR from $\mathrm{Ca}^{2+}$ e to intracellular targets such as PLC in the generation of PTHs to maintain the systemic $\left[\mathrm{Ca}^{2+}\right]$ level. Each of the mutations, however, reduced the inhibitory effect of CaSR on $\mathrm{I}_{\mathrm{NALCN}}$ when reconstituted in HEK293T cells (Figure $7 \mathrm{~A}-\mathrm{C})\left(\mathrm{I}_{1.2 \mathrm{Ca}} / \mathrm{I}_{0.1 \mathrm{Ca}}: \mathrm{A} 988 \mathrm{~V}, 0.70 \pm 0.04, \mathrm{n}=10 ; \mathrm{R} 898 \mathrm{Q}, 0.64 \pm 0.05, \mathrm{n}=10 ; \mathrm{E} 354 \mathrm{~A}, 0.79 \pm\right.$ $0.04, \mathrm{n}=9$ ), even though the protein expression levels of the mutants were comparable with that of the wild-type (Figure 7D). 
We also tested the epilepsy-associated CaSR mutations in hippocampal neurons. In cultured mouse hippocampal neurons in which the native mCaSR was knocked down, transfection of the mutant hCaSRs only partially restored $\mathrm{I}_{\mathrm{NALCN}}$ 's $\mathrm{Ca}^{2+}$ sensitivity, in contrast to those transfected with WT hCaSR (Figure 8).

\section{DISCUSSION}

We have shown that the NALCN-dependent basal $\mathrm{Na}^{+}$conductance is widely present in the central and peripheral nervous systems. Extracellular $\mathrm{Ca}^{2+}$ also regulates the conductance via a CaSR-dependent mechanism in neurons. In addition to the $\mathrm{Ca}^{2+}$-sensing ability of CaSR, a C-terminal domain of CaSR located between amino acids 888-1010, while not essential for the canonical functions of the receptor, is required for the receptor's coupling of $\mathrm{Ca}^{2+}{ }_{\mathrm{e}}$ to NALCN. The importance of such coupling is demonstrated by the epilepsy-implicated CaSR mutations that specifically disrupt the receptor's ability to regulate NALCN while maintaining the receptor's functional coupling to other conventional targets in the maintenance of systemic $\mathrm{Ca}^{2+}$ and PTH levels.

CaSR is coupled to $\mathrm{G}_{\mathrm{q} \alpha}$ and its activation leads to increases in intracellular $\mathrm{IP}_{3}$ and $\mathrm{Ca}^{2+}$ levels (Hofer and Brown, 2003). This well-established function of CaSR appears to be insufficient for the receptor's ability to regulates NALCN current. The 183 amino acids of the distal carboxy terminus of CaSR are well conserved among vertebrates, suggesting that they have physiological function, but they are not required for the receptor's ability to sense $\left[\mathrm{Ca}^{2+}\right]_{\mathrm{e}}$ changes and to trigger $\mathrm{IP}_{3}$ production (Chang et al., 2001; Gama and Breitwieser, 1998; Ray et al., 1997). In contrast, this segment is essential for the ability of CaSR to suppress I $_{\text {NALCN }}$ (Figure 6), suggesting a novel function for this intracellular tail. Consistent with this proposed function of the carboxy terminus of CaSR in NALCN regulation, but not in the $\left[\mathrm{Ca}^{2+}\right]_{\mathrm{e}}$ detection in the parathyroid gland, the R898Q mutation in the region found in human patients does not lead to abnormality in whole-body $\mathrm{Ca}^{2+}$ homeostasis; it does, however, lead to a deficiency in $\mathrm{I}_{\mathrm{LCA}}$ and is associated with heritable epilepsy (Kapoor et al., 2008). Future studies will need to investigate the structural basis underlying this domain's involvement in the coupling between CaSR and the NALCN channel complex. 


\section{FIGURES}
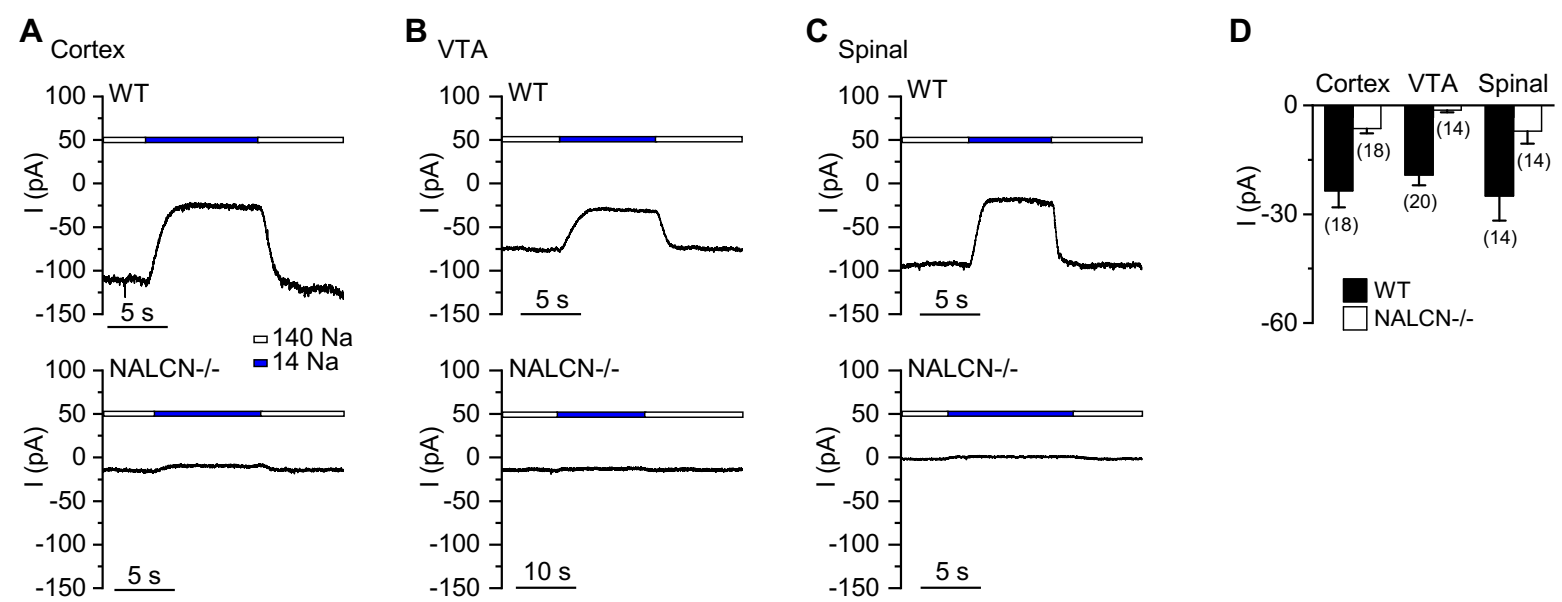

Figure 1. NALCN-dependent $\mathrm{Na}^{+}$-leak conductance is widely expressed the brain and spinal cord

$\mathrm{Na}^{+}$-leak currents ( $\mathrm{I}_{\text {LNA }}$ ) were measured as changes in the sizes of holding currents (at $-68 \mathrm{mV}$ ) upon a reduction of extracellular $\left[\mathrm{Na}^{+}\right]$from $140 \mathrm{mM}$ to $14 \mathrm{mM}$. (A-C) Representative holding currents recorded from wild-type (WT, upper traces) and NALCN KO (NALCN-/-, lower traces) cortical (A), VTA (B) and spinal cord (C) neurons. (D) Average I INA sizes. Numbers of cells recorded are given in parentheses. Data is presented as mean \pm S.E. 


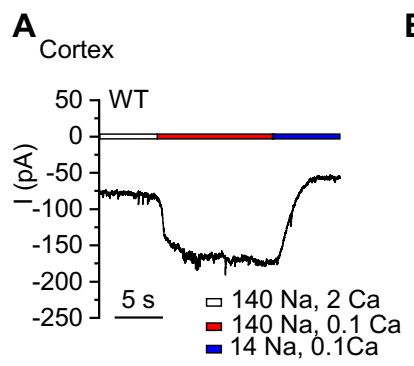

B VTA

C Spinal $_{\text {San }}$
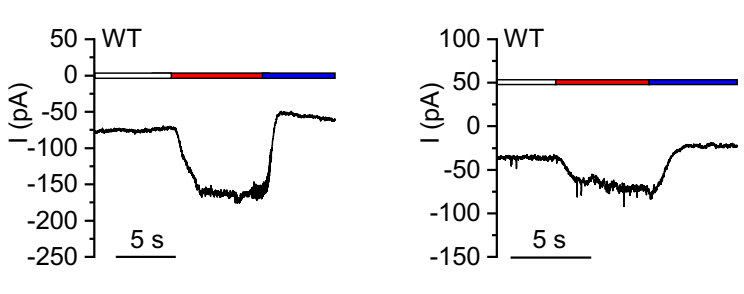

D
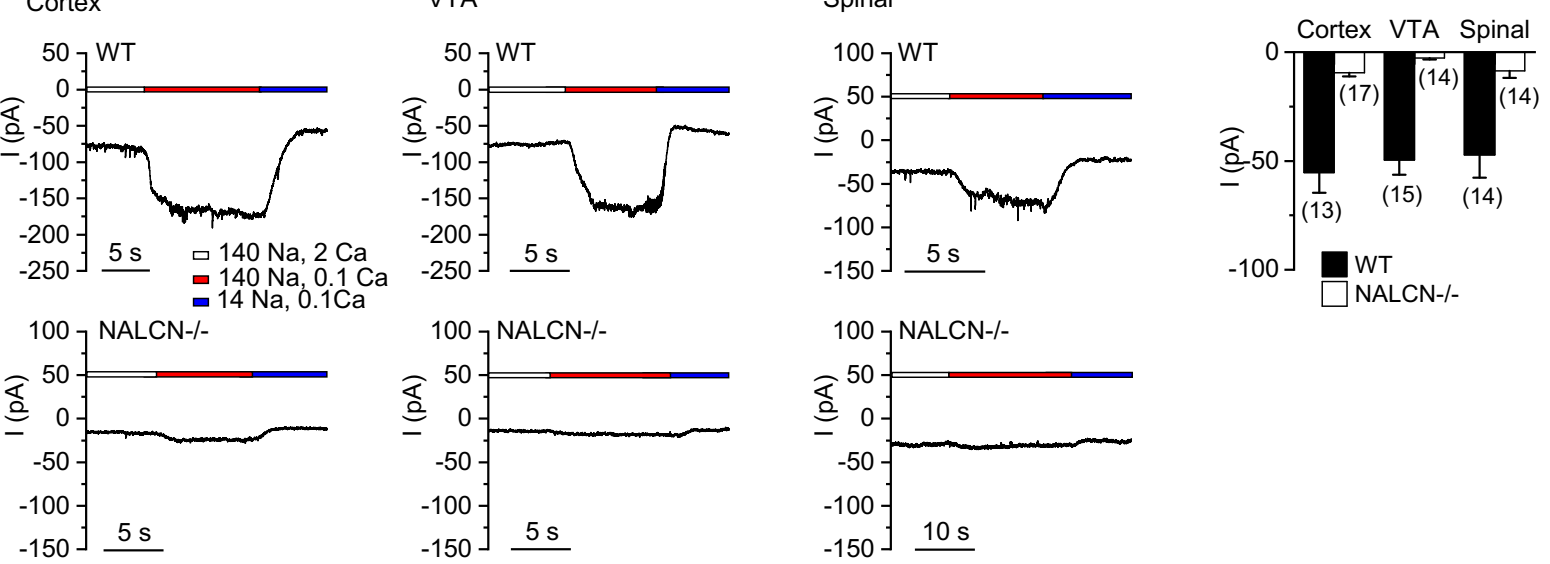

Figure 2. Extracellular $\mathrm{Ca}^{2+}$ regulates NALCN-dependent $\mathrm{Na}^{+}$currents in the brain and spinal cord

Low $\left[\mathrm{Ca}^{2+}\right]_{\mathrm{e}}$ - induced NALCN-dependent leak currents ( $\left.\mathrm{I}_{\mathrm{LCA}}\right)$ were measured as the changes in the sizes of holding currents (at $-68 \mathrm{mV}$ ) when extracellular $\left[\mathrm{Ca}^{2+}\right]$ was lowered from $2 \mathrm{mM}(2$ $\left.\mathrm{Ca}^{2+}\right)$ to $0.1 \mathrm{mM}\left(0.1 \mathrm{Ca}^{2+}\right)$. In the end of each recording, bath was switch from the one containing $140 \mathrm{mM} \mathrm{Na}^{+}$to one with $14 \mathrm{mM} \mathrm{Na}^{+}\left(126 \mathrm{mM} \mathrm{Na}^{+}\right.$replaced with NMDG) to ensure that the increase of holding currents in low $\left[\mathrm{Ca}^{2+}\right]$ containing bath was not due to non-specific leak. (A-C) Representative currents recorded from a wild-type (upper traces) and Nalcn $\mathrm{KO}$ (lower traces) cortical (A), VTA (B) and spinal cord (C) neurons. (D) Averaged ILCA sizes. 

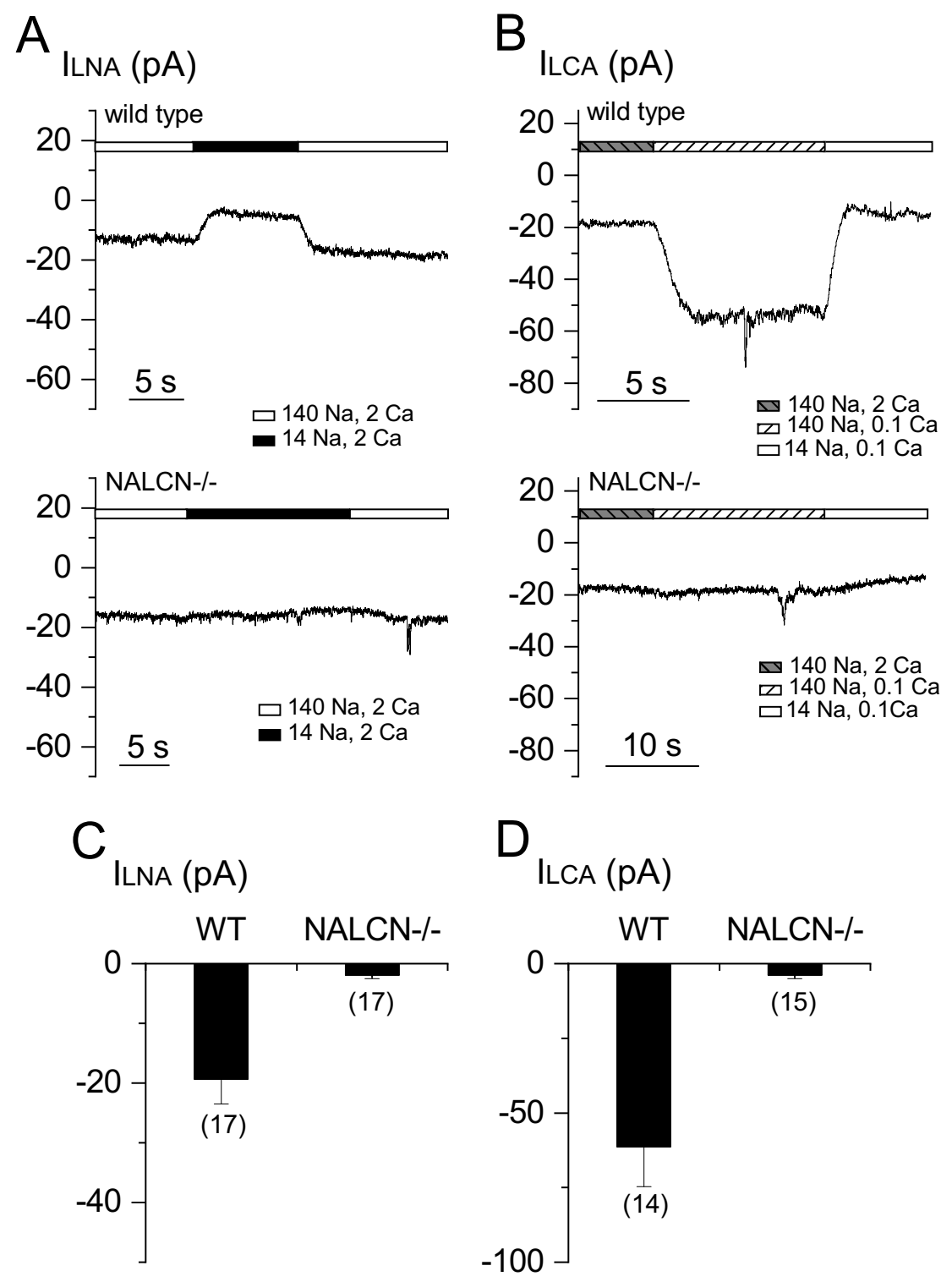

Figure 3. Extracellular $\mathrm{Ca}^{2+}$ regulates $\mathrm{Na}^{+}$-leak currents in peripheral neurons

(A, B) Representative I INA (recorded with $140 \mathrm{mM} \mathrm{Na}^{+}$-containing bath) (A) and $\mathrm{I}_{\mathrm{LCA}}(\mathbf{B})$ recorded in DRG neurons cultured from wild type (WT, upper panels) and NALCN knockout (NALCN-/-, lower panels) mice. (C, D) Averaged sizes of the $\mathrm{I}_{\mathrm{LNA}}(\mathbf{C})$ and $\mathrm{I}_{\mathrm{LCA}}(\mathbf{D})$. 


\section{A}

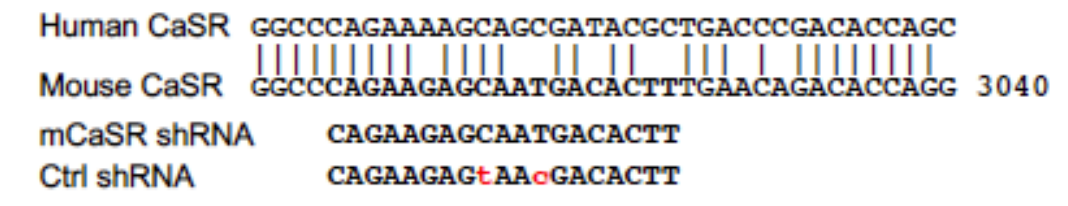

$\begin{array}{lllllllll}\text { B } & & & & & & & & \\ \text { mCaSR } & - & + & + & + & + & + & + & + \\ \text { shRNA } & - & + & - & - & - & - & - & - \\ \text { ctrl shRNA } & - & - & + & + & + & + & + & + \\ \text { loading }(\%) & 100 & 100 & 100 & 50 & 40 & 30 & 20 & 10\end{array}$
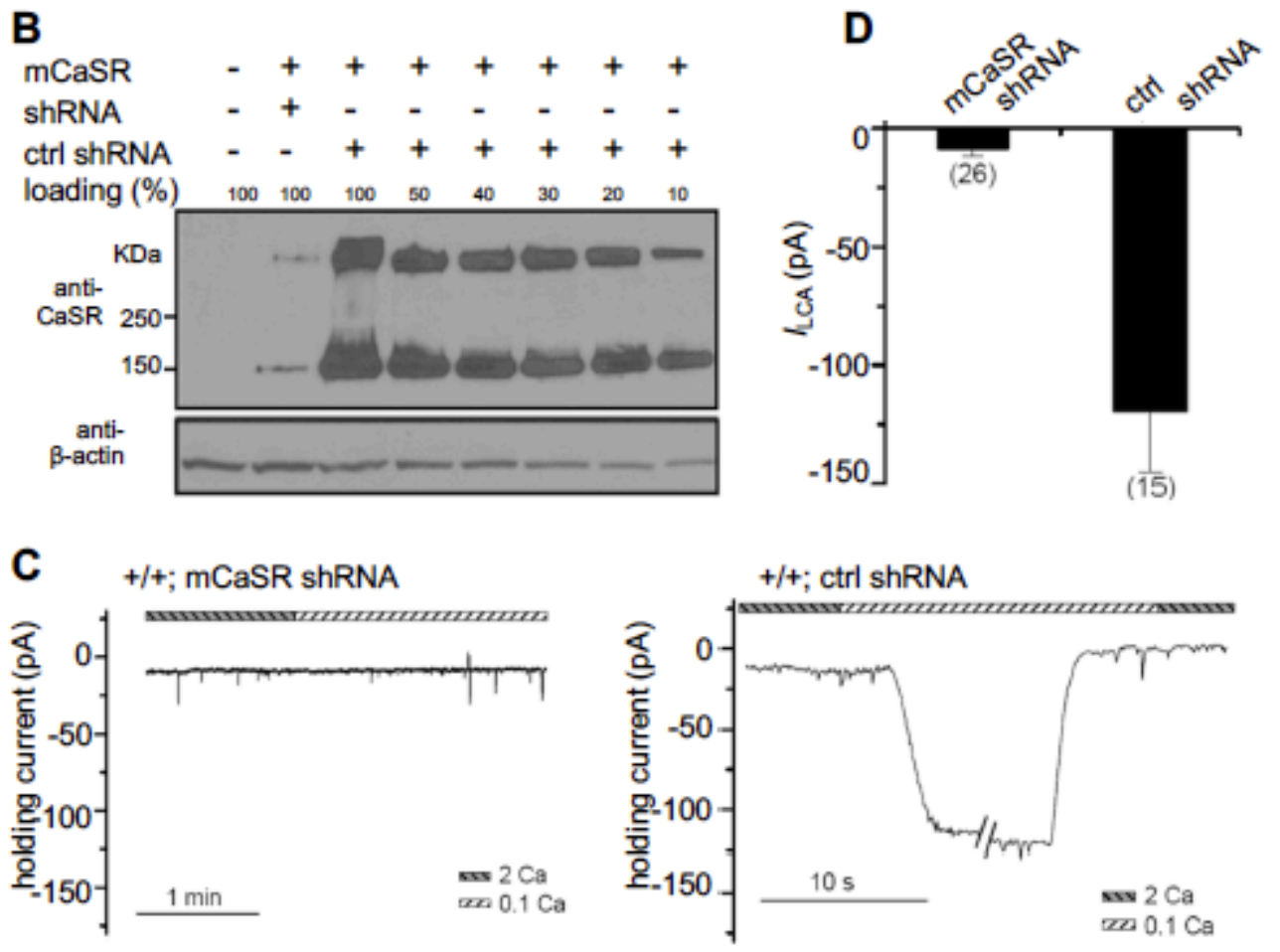

Figure 4. CaSR is required for the regulation of $\mathrm{NALCN}$ currents by extracellular $\mathrm{Ca}^{2+}$ in neurons

(A) Design of an shRNA specific to the mouse CaSR (mCaSR). Upper: alignment of human (h) and mouse (m) CaSR sequences in the region targed by the shRNA. Lower: sequence of the shRNA target against mCaSR and that of a control shRNA with mismatches at two base pairs. (B) Western-blots showing the knockdown efficiency of the shRNA. CaSR protein levels were detected with cell lysates from HEK293T cells co-transfected with mouse CaSR cDNA (mCaSR) and the shRNA against mCaSR or the missense shRNA as control. Decreasing amounts of total cell lysates from the "mCaSR + missense shRNA"-transfected cells were loaded to determine the knockdown efficiency. "100\%" indicates the amount equal to that used from the non-transfected cells. Anti- $\beta$-actin was used as the loading control. The upper bands in the blot with anti-CaSR represent protein dimmers. (C) Representative $\mathrm{I}_{\mathrm{LCA}}$ recordings in WT hippocampal neurons transfected with shRNA against mouse CaSR (left panel) or the missense shRNA as control (right panel). (D) Summary of the I LCA $_{\text {current sizes. }}$ 
$\mathbf{A}_{\text {neuron }}$

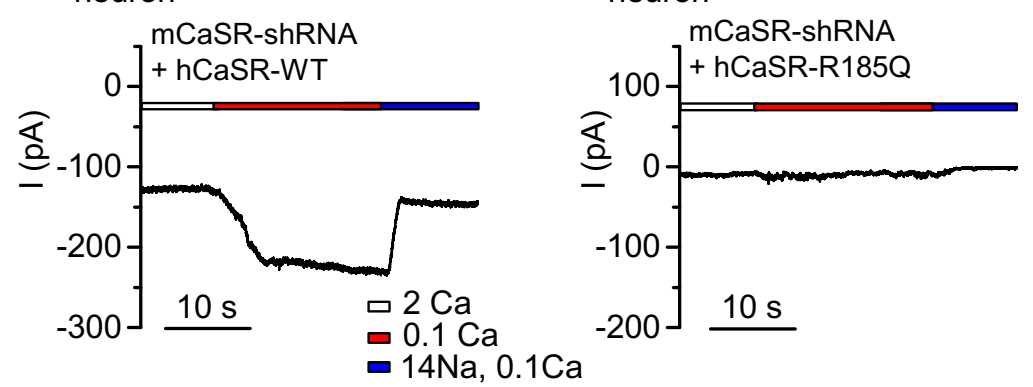

D NALCN + UNC80 + WT CaSR

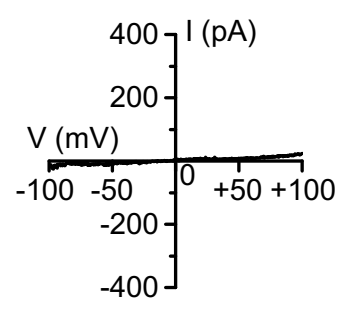

$1.2 \mathrm{Ca}$

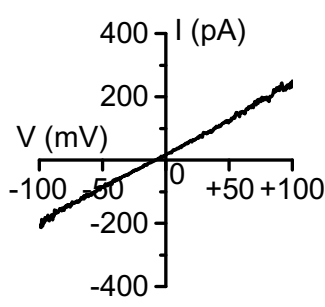

$0.1 \mathrm{Ca}$

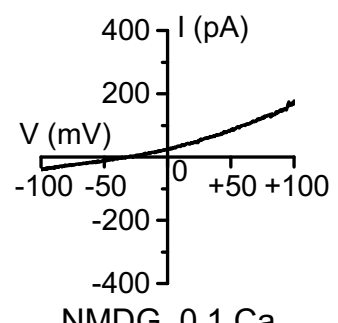

NMDG, $0.1 \mathrm{Ca}$
$C_{\text {neuron }}$

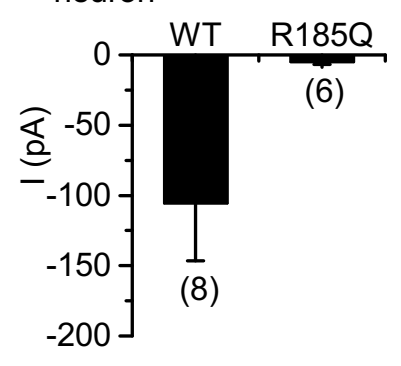

$\mathbf{F}_{\text {HEK293T }}$

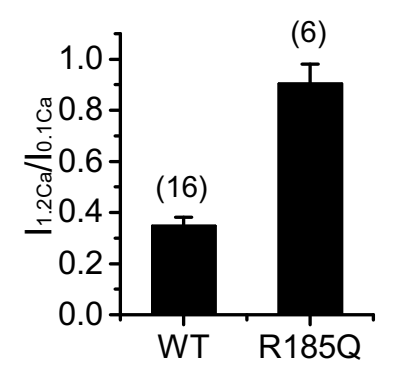

E NALCN + UNC80 + CaSR-R185Q

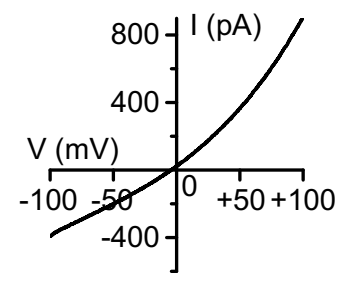

$1.2 \mathrm{Ca}$

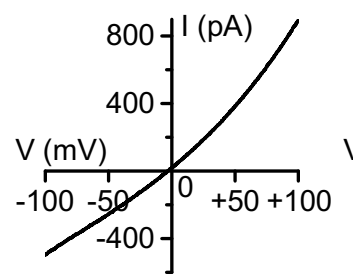

$0.1 \mathrm{Ca}$

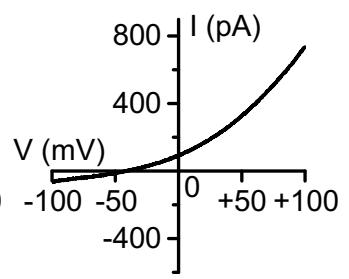

NMDG, $0.1 \mathrm{Ca}$

Figure 5. CaSR's $\mathrm{Ca}^{2+}$-sensing ability is required for the receptor's regulation of NALCN currents

(A-C) Representative ILCA recordings in WT mouse hippocampal neurons transfected with a wild-type (A) or R185Q mutant (B) human CaSR cDNA. The endogenous mCaSR was knocked down with co-transfection of the mCaSR-specific shRNA. Summary of ILCA sizes are

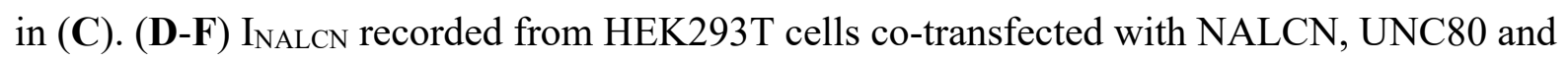
a wild-type human CaSR (D) or the R185Q mutant (E), recorded with $1.2 \mathrm{mM}(1.2 \mathrm{Ca}$, left panels $)$ or $0.1 \mathrm{mM}(0.1 \mathrm{Ca}$, middle panels $) \mathrm{Ca}^{2+}$ in the bath. In the end of recording, bath was perfused with one in which $\mathrm{Na}^{+}$and $\mathrm{K}^{+}$were replaced with NMDG (right panels). A ramp protocol was used $\left(-100 \mathrm{mV}\right.$ to $+100 \mathrm{mV}$ in $\left.1 \mathrm{~s}, \mathrm{~V}_{\mathrm{h}}=0 \mathrm{mV}\right)$. In $(\mathbf{F})$, the $\mathrm{Ca}^{2+}$-sensitivity of $\mathrm{I}_{\mathrm{NALCN}}$ is represented as the ratio of the sizes of current (at $-100 \mathrm{mV}$ ) recorded with bath containing $1.2 \mathrm{mM}\left(\mathrm{I}_{1.2 \mathrm{Ca}}\right)$ and that recorded with $0.1 \mathrm{mM} \mathrm{Ca}^{2+}$-containing bath $\left(\mathrm{I}_{0.1 \mathrm{Ca}}\right)$. 


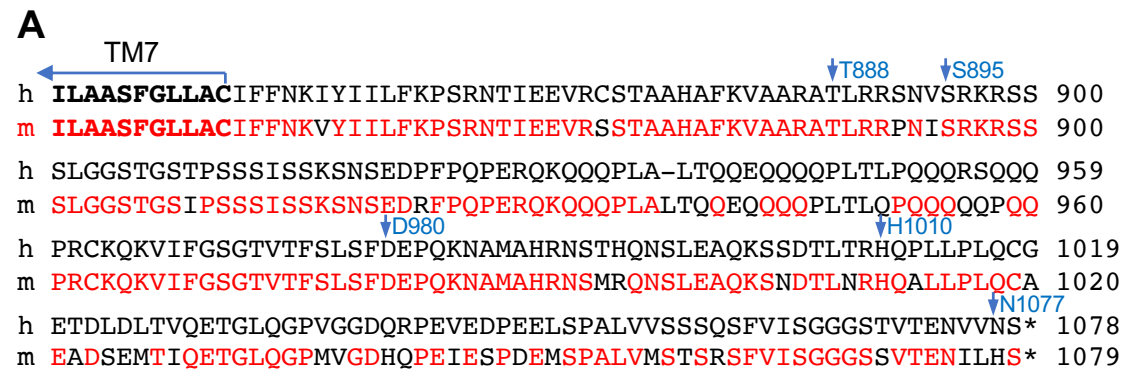

B neuron

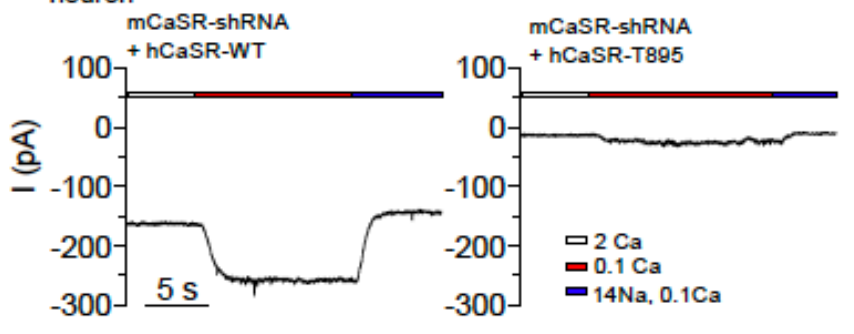

D HEK293T, NALCN + UNC80 + WT CaSR
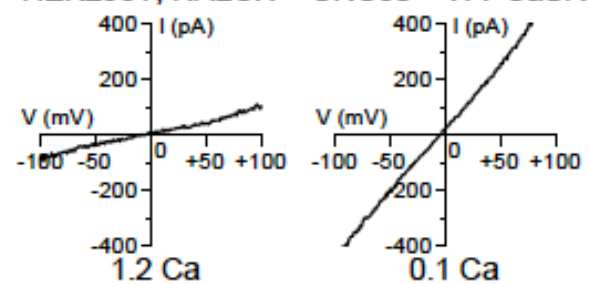

$0.1 \mathrm{Ca}$

HEK293T, NALCN + UNC80 + CaSR(1-888)

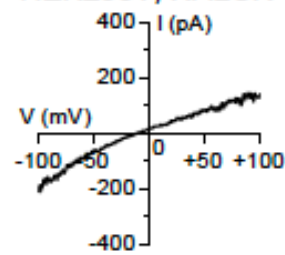

$1.2 \mathrm{Ca}$

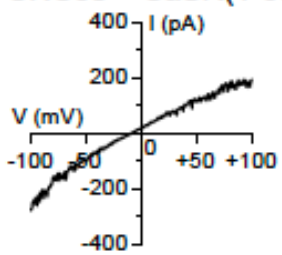

$0.1 \mathrm{Ca}$

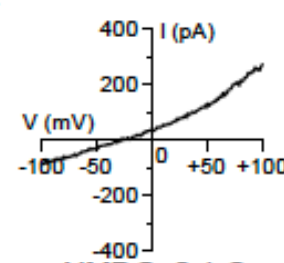

NMDG, $0.1 \mathrm{Ca}$

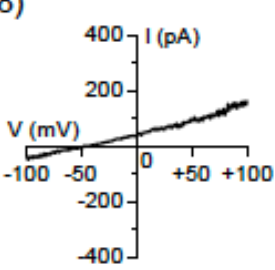

NMDG, $0.1 \mathrm{Ca}$

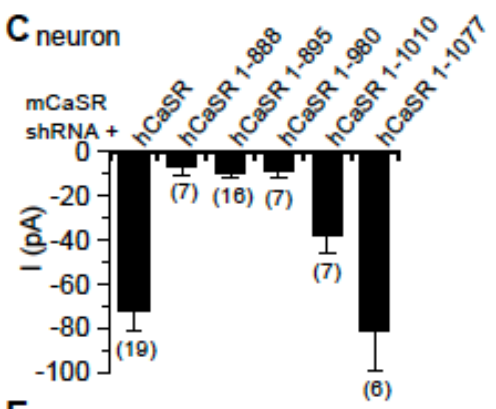

$\mathbf{E}_{\text {HEK293T }}$

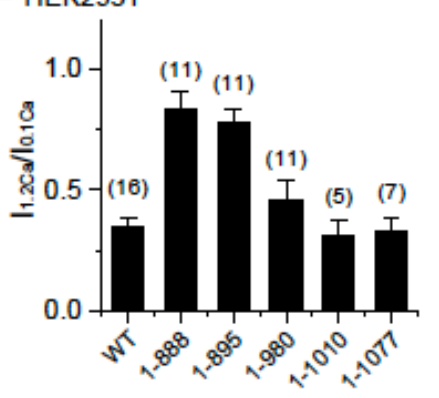

Figure 6. The C-terminus of CaSR is required for its ability to regulate NALCN

(A) Sequence alignment of the C-termini of human (h) and mouse (m) CaSR. Mouse 
sequences conserved with those in human are in red. (B) Representative $\mathrm{I}_{\mathrm{LCA}}$ recorded in mouse hippocampal neurons co-transfected with mCaSR shRNA and full-length hCaSR or a mutant truncated after T895 (hCaSR-T895). (C) Averaged amplitudes of $\mathrm{I}_{\mathrm{LCA}}$ recorded in mouse hippocampal neurons co-transfected with mCaSR shRNA and full-length hCaSR or mutant hCaSR with truncation as indicated. (D, E) I IALCN recorded from HEK293T cells co-transfected with NALCN, UNC80 and a wild-type human CaSR or a mutant truncated at T888, recorded with $1.2 \mathrm{mM}$ (1.2 Ca, left panels in D) or $0.1 \mathrm{mM}(0.1 \mathrm{Ca}$, middle panels) $\mathrm{Ca}^{2+}$ in the bath. In the end of recording, bath was perfused with one in which $\mathrm{Na}^{+}$and $\mathrm{K}^{+}$ replaced with NMDG (right panels). A ramp protocol was used $(-100 \mathrm{mV}$ to $+100 \mathrm{mV}$ in $1 \mathrm{~s}$, $\mathrm{V}_{\mathrm{h}}=0 \mathrm{mV}$ ). (E) $\mathrm{Ca}^{2+}$-sensitivity of $\mathrm{I}_{\mathrm{NALCN}}$ is plotted as the ratio of the sizes of current (at $-100 \mathrm{mV}$ ) recorded with bath containing $1.2 \mathrm{mM}\left(\mathrm{I}_{1.2 \mathrm{Ca}}\right)$ and that recorded with $0.1 \mathrm{mM}$ $\mathrm{Ca}^{2+}$-containing bath $\left(\mathrm{I}_{0.1 \mathrm{Ca}}\right)$. The ratio for $\mathrm{WT}$ was replotted from Figure $5 \mathrm{~F}$ for comparison. 
A

CaSR R898Q + UNC80 + NALCN

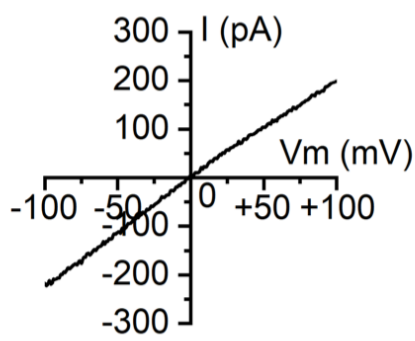

$1.2 \mathrm{Ca}$

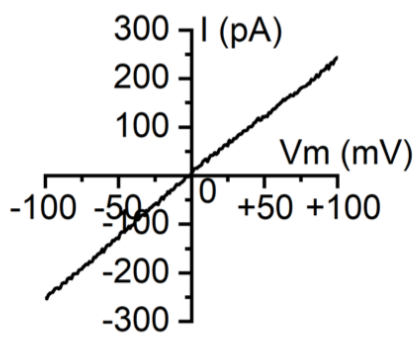

$0.1 \mathrm{Ca}$

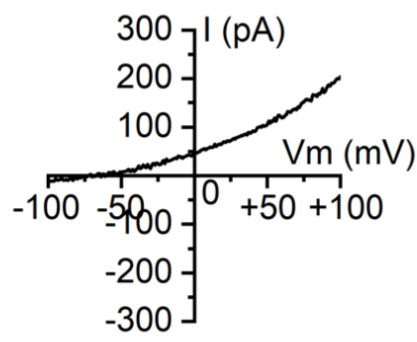

NMDG, $0.1 \mathrm{Ca}$

B

CaSR E354A + UNC80 + NALCN

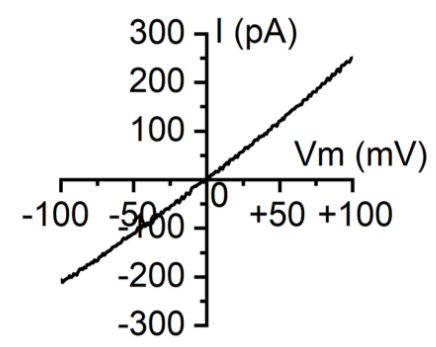

$1.2 \mathrm{Ca}$

C

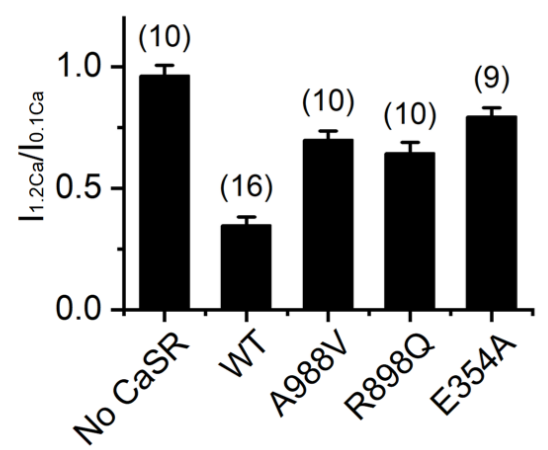

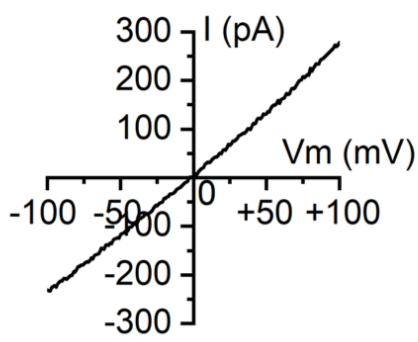

$0.1 \mathrm{Ca}$

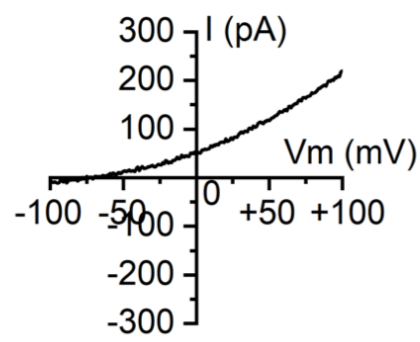

NMDG, $0.1 \mathrm{Ca}$

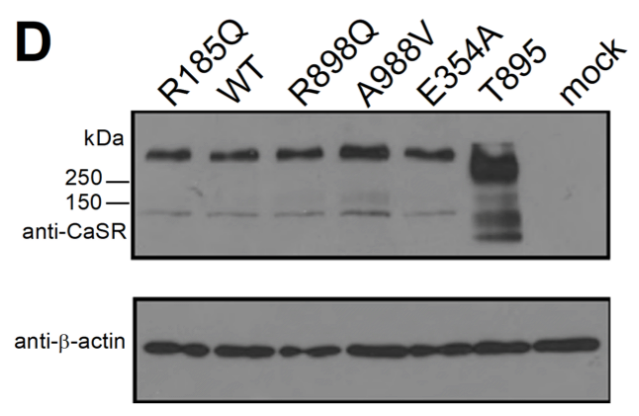

Figure 7. Epilepsy-associated mutations in CaSR disrupt CaSR's ability to regulate NALCN in HEK293T cells

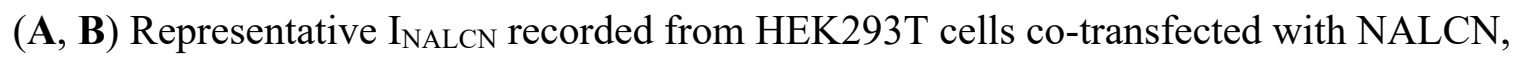
UNC80 and human CaSR mutants R898Q (A) or E354A (B), recorded with $1.2 \mathrm{mM}(1.2 \mathrm{Ca}$, left panels $)$ or $0.1 \mathrm{mM}(0.1 \mathrm{Ca}$, middle panels $) \mathrm{Ca}^{2+}$ in the bath. In the end of recording, bath was perfused with one in which $\mathrm{Na}^{+}$and $\mathrm{K}^{+}$replaced with NMDG (right panels). A ramp protocol was used $\left(-100 \mathrm{mV}\right.$ to $+100 \mathrm{mV}$ in $\left.1 \mathrm{~s}, \mathrm{~V}_{\mathrm{h}}=0 \mathrm{mV}\right)$. (C) Averaged $\mathrm{Ca}^{2+}$-sensitivity of $\mathrm{I}_{\mathrm{NALCN}}$ reconstituted with WT or mutant CaSR, as represented as the ratio of the sizes of current (at $-100 \mathrm{mV}$ ) recorded with bath containing $1.2 \mathrm{mM}\left(\mathrm{I}_{1.2 \mathrm{Ca}}\right)$ and that recorded with 0.1 
$\mathrm{mM} \mathrm{Ca}{ }^{2+}$-containing bath $\left(\mathrm{I}_{0.1 \mathrm{Ca}}\right)$. The ratio for WT was replotted from Figure 5F for comparison. (D) Western blot with anti-CaSR or anti- $\beta$-actin (for loading control) of lysates of HEK293T cells transfected with empty vector (mock), WT or mutant hCaSR as indicated. The carboxy-terminal truncated CaSR mutant (CaSR 1-895) gave rise to apparently higher level of protein when the same amount of DNA $(2 \mu \mathrm{g})$ as the wild-type was used for transfection. Recordings were also done with 1/3 amount of CaSR 1-895 (0.7 $\mu \mathrm{g})$ as normally used $(2 \mu \mathrm{g})$; still, no obvious suppression of the NALCN current was observed (I1.2Ca/I0.1Ca $=95.9 \pm 17.6 \% ; \mathrm{n}=8)$. 

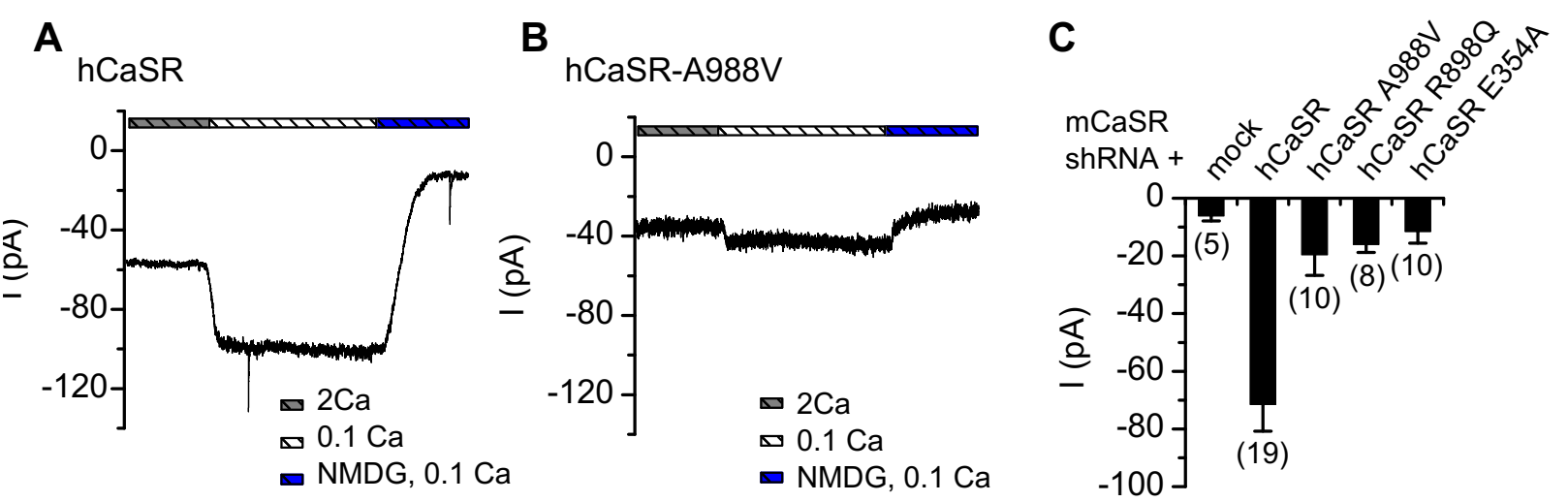

Figure 8. Epilepsy-associated mutations in CaSR's C-terminus disrupt $\mathrm{I}_{\mathrm{LCA}}$ in neurons

(A, B) Representative $\mathrm{I}_{\mathrm{LCA}}$ recordings in WT hippocampal neurons transfected with the wild-type (A) or A99V mutant (B) human CaSR cDNA. The endogenous mouse CaSR was knocked down with co-transfection of the mouse CaSR-specific shRNA. Summary of the ILCA current sizes with transfection of wild-type and the epilepsy-associated mutant hCaSR as indicated are in $(\mathbf{C})$. 


\section{EXPERIMENTAL PROCEDURES}

\section{Animals}

Animal uses were approved by the University of Pennsylvania IACUC. The development of NALCN knockout was previously described (Lu et al., 2007). P0 pups were obtained from matings between heterozygous. Littermates were used as controls.

\section{DNA constructs}

The cDNA constructs encoding NALCN (rat), UNC80 (mouse, in vector pcDNA3.1(+)) and Src were previously described (Lu et al., 2007; Lu et al., 2009; Lu et al., 2010). The NALCN construct was made in a vector based on pTracer-CMV2 (Invitrogen) and modified to also express eGFP under a separate promoter. Human CaSR was amplified from an IMAGE EST clone (ID\#8327704) and subcloned into the NotI and XbaI sites of a vector based on pTracer-CMV2 modified to also express mCherry RFP under a separate promoter for the identification of transfected cells. CaSR mutants were constructed by introducing point mutations using PCR methods as follows: R185Q (nt554/G mutated to A; with the first nucleotide (nt) in the open reading frame numbered as 1), E354A (nt1065/A to C), R898Q (nt 2693/G to A), A988V (nt2963/C to T), CaSR1-895 (nt2686-2688/CGC to TGA; amino acid 896 mutated to a stop codon). The mouse CaSR open reading frame used for the test of shRNA efficiency was amplified from mouse kidney cDNA and subcloned into the HindIII and SacII sites of peGFP-N1. The shRNA constructs were cloned into the GFP-containing vector pG-Super (Kojima et al., 2004) (a gift from Dr. Tatyana Svitkina) cut with BglII and HindIII, according to the manual of pSuper vector, with targeting sequence of CAGAAGAGCAATGACACTT. The mis-match control shRNA has a target sequence of CAGAAGAGtAAcGACACTT, with two mismatches to the mCaSR sequence. All DNA constructs were confirmed with sequencing.

\section{Cell culture and transfection}

All the cells were maintained in humidified incubators at $37^{\circ} \mathrm{C}$ and $5 \% \mathrm{CO}_{2}$. $\mathrm{HEK} 293 \mathrm{~T}$ cells (from ATCC) were cultured in DMEM (Gibco) medium supplemented with 1x penicillin-streptomycin (Pen-Strep, Gibco) and 10\% FBS (Atlanta biologicals and BioWhittaker). Mouse hippocampal and spinal cord neurons were cultured from P0 as previously described (Lu et al., 2007; Lu et al., 2010). Briefly, dissected tissues were digested with papain (Worthington) and plated on poly-L-lysine-coated glass coverslips in 35-mm dishes at a density of $\sim 3-4 \times 10^{5}$ cells/dish, in 80\% DMEM (Lonza), 10\% Ham's F-12 (Lonza), $10 \%$ bovine calf serum (iron supplemented, Hyclone) and $0.5 \mathrm{x}$ Pen-Strep. Medium was changed the next day to Neurobasal A medium supplemented with $2 \%$ B-27, 0.5x Pen-Strep, 
and 1x Glutamax (all from Gibco). VTA neurons were cultured similar to hippocampal neurons except that neurons were plated in the Neurobasal A-based medium on the first day. DRGs were dissected from P10 pups in ice-cold DMEM (Gibco) and were digested for 60 min at $37^{\circ} \mathrm{C}$ in a $35-\mathrm{mm}$ dish with $1.5 \mathrm{ml}$ DMEM, $4 \mathrm{mg}$ collagenase type 2 (Worthington) and $1.5 \mathrm{mg}$ trypsin (Worthington). Digestion was stopped with $1 \mathrm{ml}$ culture medium containing 80\% DMEM (Lonza), 10\% BCS (Hylcone), 10\% Ham’s F12 (Lonza), 0.5\% Pen-Strep (Gibco). Cells were dissociated by pipetting up and down, and were plated onto poly-lysine coated coverslips in culture medium. Medium was changed the next day and once a week after. Cytosine arabinoside (ARAC, Sigma) was added at $5 \mu \mathrm{M}$ to the medium when needed to suppress the growth of fibroblast.

DNA transfections were performed using Lipofectamine 2000 (Invitrogen) according to the manufacture's instruction. Recordings were done 48-72 hr later. For I $\mathrm{LCA}_{\mathrm{L}}$ recording in HEK293T cells, cells ( $\sim 90 \%$ confluency) plated on a $35-\mathrm{mm}$ dish were transfected with 0.5 $\mu \mathrm{g}$ NALCN, $0.5 \mu \mathrm{g}$ UNC80, $0.5 \mu \mathrm{g}$ Src529 (a constitutively activated Src kinase), and $2 \mu \mathrm{g}$ CaSR cDNA unless otherwise stated. In control experiments where one or more constructs were not included, an equal amount of empty vector DNA was added to ensure that all the transfections had the same amount of DNA. Cells were re-plated on the day of recording. Only cells with moderate level of both GFP and RFP fluorescence signals were selected for recordings. Neurons between DIV 5 and 7 were used for transfection. For shRNA knockdown in hippocampal neurons, $3 \mu \mathrm{g}$ shRNA DNA was used for a $35 \mathrm{~mm}$ dish. For knockdown-and-reconstitution in neurons, $2 \mu \mathrm{g}$ shRNA DNA and $1 \mu \mathrm{g}$ CaSR DNA was co-transfected. DNAs used for neuronal transfection were endotoxin-free.

\section{Western blot}

HEK293T cells in $35 \mathrm{~mm}$ dishes were lysed by incubation at $4^{\circ} \mathrm{C}$ for $1 \mathrm{hr}$ in $300 \mu \mathrm{RIPA}$ buffer (50 mM Tris- $\mathrm{HCl}, 150 \mathrm{mM} \mathrm{NaCl}, 1 \% \mathrm{NP}-40,0.5 \%$ (w/v) deoxycholate, $0.1 \%$ (w/v) SDS, pH 7.4) supplemented with a protease inhibitor cocktail (PIC, Roche). After centrifuging for $30 \mathrm{~min}$ at $20,000 \mathrm{~g}$, the supernatant was transferred to a fresh tube.

Protein electrophoresis was performed with 10\% SDS-PAGE gel in Tris-glycine-SDS running buffer or 4-12\% Bis-Tris gradient gels in MOPS-SDS running buffer (Invitrogen). Proteins were transferred onto polyvinylidene difluoride (PVDF) membranes. After being blocked with 5\% nonfat dry milk in PBS with 0.1\% Tween-20 (PBST), membranes were incubated with primary antibodies $(1 \mu \mathrm{g} / \mathrm{ml})$ at $4^{\circ} \mathrm{C}$ overnight. Following incubation with horseradish-peroxidase-labeled secondary antibodies for $1 \mathrm{hr}$ at room temperature, 
membranes were developed with SuperSignal West Pico ECL or SuperSignal West Dura ECL. The anti-CaSR antibody (monoclonal, against aa 15-29) was from Santa Cruz (cat \#Sc-47741).

\section{Electrophysiology}

For HEK293T cell recordings, the pipette solution contained (in mM) $150 \mathrm{Cs}, 120 \mathrm{Mes}, 10$ $\mathrm{NaCl}, 10$ EGTA, $4 \mathrm{CaCl}_{2}, 0.3 \mathrm{Na}_{2} \mathrm{GTP}, 2 \mathrm{Mg}$-ATP, 10 HEPES (pH 7.4, osmolarity of 300 $\mathrm{mOsm} / \mathrm{L}$ ). Bath contained (in $\mathrm{mM}$ ) $150 \mathrm{NaCl}, 3.5 \mathrm{KCl}, 1 \mathrm{MgCl}_{2}, 10 \mathrm{HEPES}, 20$ glucose, and $\mathrm{CaCl}_{2}$ as indicated (pH 7.4 with $5 \mathrm{NaOH}, \sim 320 \mathrm{mOsm} / \mathrm{L}$ ). In the NMDG-containing bath, $\mathrm{Na}^{+}$ and $\mathrm{K}^{+}$were replaced with $\mathrm{NMDG}^{+}$. The inclusion of $\sim \mathrm{mM} \mathrm{Mg}^{2+}$ in both pipette and bath solutions minimizes the contamination of the endogenous $\mathrm{Mg}^{2+}$-inhibited TRPM7 currents present in HEK293 cells (Chokshi et al., 2012; Chubanov et al., 2012).

For recording from neurons, pipette solution contained (in $\mathrm{mM}$ ) $120 \mathrm{CsCl}, 4 \mathrm{EGTA}, 2 \mathrm{CaCl}_{2}$, $2 \mathrm{MgCl}_{2}, 4 \mathrm{Mg}$-ATP, 0.3 Tris-GTP, 14 phosphocreatine (di-tris salt) and 10 HEPES (pH 7.4). The $140 \mathrm{mM} \mathrm{Na}^{+}$-containing bath contained (in $\mathrm{mM}$ ) $140 \mathrm{NaCl}, 5 \mathrm{KCl}, 2$ (or 0.1 ) $\mathrm{CaCl}_{2}, 1$ $\mathrm{MgCl}_{2}, 6$ glucose, $2 \mathrm{CsCl}$ and 10 HEPES (pH 7.4). In the $14 \mathrm{mM} \mathrm{Na-containing} \mathrm{bath,} 126$ $\mathrm{mM} \mathrm{NaCl}$ was replaced with $126 \mathrm{mM}$ Tris-Cl. To block voltage-gated $\mathrm{Na}^{+}$channels and synaptic currents, TTX $(1 \mu \mathrm{M})$, APV $(10 \mu \mathrm{M})$, bicuculline $(20 \mu \mathrm{M})$ and CNQX $(20 \mu \mathrm{M})$ were added to the bath.

Patch clamp recordings were performed using an Axopatch-200A and a MultiClamp 700B amplifier controlled with Clampex 9.2 or Clampex 10 software (Axon). Signals were digitized at $2-10 \mathrm{kHz}$ with a Digidata $1322 \mathrm{~A}$ or 1440 digitizer. Liquid junction potentials (estimated using Clampex software) were corrected offline. 


\section{ACKNOWLEDGMENTS}

We thank members of the Ren lab for help and discussions. The work was supported, in part, by NIH grants 1R01NS074257 and 1R01NS055293 (to D.R.).

\section{REFERENCES}

Al-Sayed, M.D., Al-Zaidan, H., Albakheet, A., Hakami, H., Kenana, R., Al-Yafee, Y., Al-Dosary, M., Qari, A., Al-Sheddi, T., Al-Muheiza, M., et al. (2013). Mutations in NALCN cause an autosomal-recessive syndrome with severe hypotonia, speech impairment, and cognitive delay. American journal of human genetics 93, 721-726.

Amzica, F., Massimini, M., and Manfridi, A. (2002). Spatial buffering during slow and paroxysmal sleep oscillations in cortical networks of glial cells in vivo. J Neurosci 22, 1042-1053.

Angius, A., Cossu, S., Uva, P., Oppo, M., Onano, S., Persico, I., Fotia, G., Atzeni, R., Cuccuru, G., Asunis, M., et al. (2018). Novel NALCN biallelic truncating mutations in siblings with IHPRF1 syndrome. Clinical genetics.

Aoyagi, K., Rossignol, E., Hamdan, F.F., Mulcahy, B., Xie, L., Nagamatsu, S., Rouleau, G.A., Zhen, M., and Michaud, J.L. (2015). A Gain-of-Function Mutation in NALCN in a Child with Intellectual Disability, Ataxia, and Arthrogryposis. Hum Mutat 36, 753-757.

Bai, M., Pearce, S.H., Kifor, O., Trivedi, S., Stauffer, U.G., Thakker, R.V., Brown, E.M., and Steinmann, B. (1997). In vivo and in vitro characterization of neonatal hyperparathyroidism resulting from a de novo, heterozygous mutation in the $\mathrm{Ca} 2+$-sensing receptor gene: normal maternal calcium homeostasis as a cause of secondary hyperparathyroidism in familial benign hypocalciuric hypercalcemia. J Clin Invest 99, 88-96.

Bai, M., Trivedi, S., and Brown, E.M. (1998). Dimerization of the extracellular calcium-sensing receptor $(\mathrm{CaR})$ on the cell surface of CaR-transfected HEK293 cells. J Biol Chem 273, 23605-23610.

Benninger, C., Kadis, J., and Prince, D.A. (1980). Extracellular calcium and potassium changes in hippocampal slices. Brain Res 187, 165-182.

Berridge, M.J., Bootman, M.D., and Roderick, H.L. (2003). Calcium signalling: dynamics, homeostasis and remodelling. Nat Rev Mol Cell Biol 4, 517-529.

Brown, E.M., Gamba, G., Riccardi, D., Lombardi, M., Butters, R., Kifor, O., Sun, A., Hediger, M.A., Lytton, J., and Hebert, S.C. (1993). Cloning and characterization of an extracellular $\mathrm{Ca}(2+)$-sensing receptor from bovine parathyroid. Nature $366,575-580$.

Brown, E.M., and MacLeod, R.J. (2001). Extracellular calcium sensing and extracellular calcium signaling. Physiol Rev 81, 239-297. 
Campbell, J., FitzPatrick, D.R., Azam, T., Gibson, N.A., Somerville, L., Joss, S.K., Deciphering Developmental Disorders, S., and Urquhart, D.S. (2018). NALCN Dysfunction as a Cause of Disordered Respiratory Rhythm With Central Apnea. Pediatrics 141, S485-S490.

Chang, W., Pratt, S., Chen, T.H., Bourguignon, L., and Shoback, D. (2001). Amino acids in the cytoplasmic $\mathrm{C}$ terminus of the parathyroid $\mathrm{Ca} 2+$-sensing receptor mediate efficient cell-surface expression and phospholipase C activation. J Biol Chem 276, 44129-44136.

Chen, W., Bergsman, J.B., Wang, X., Gilkey, G., Pierpoint, C.R., Daniel, E.A., Awumey, E.M., Dauban, P., Dodd, R.H., Ruat, M., et al. (2010). Presynaptic external calcium signaling involves the calcium-sensing receptor in neocortical nerve terminals. PLoS One 5, e8563.

Chokshi, R., Matsushita, M., and Kozak, J.A. (2012). Detailed examination of Mg2+ and pH sensitivity of human TRPM7 channels. Am J Physiol Cell Physiol 302, C1004-1011.

Chong, J.X., McMillin, M.J., Shively, K.M., Beck, A.E., Marvin, C.T., Armenteros, J.R., Buckingham, K.J., Nkinsi, N.T., Boyle, E.A., Berry, M.N., et al. (2015). De novo mutations in NALCN cause a syndrome characterized by congenital contractures of the limbs and face, hypotonia, and developmental delay. American journal of human genetics 96, 462-473.

Chua, H.C., Wulf, M., Weidling, C., Rasmussen, L.P., and Pless, S.A. (2020). The NALCN channel complex is voltage sensitive and directly modulated by extracellular calcium. Sci Adv 6, eaaz3154.

Chubanov, V., Mederos y Schnitzler, M., Meissner, M., Schafer, S., Abstiens, K., Hofmann, T., and Gudermann, T. (2012). Natural and synthetic modulators of SK (K(ca)2) potassium channels inhibit magnesium-dependent activity of the kinase-coupled cation channel TRPM7. Br J Pharmacol 166, 1357-1376.

Clapham, D.E. (2007). Calcium signaling. Cell 131, 1047-1058.

Dershem, R., Gorvin, C.M., Metpally, R.P.R., Krishnamurthy, S., Smelser, D.T., Hannan, F.M., Carey, D.J., Thakker, R.V., Breitwieser, G.E., and Regeneron Genetics, C. (2020).

Familial Hypocalciuric Hypercalcemia Type 1 and Autosomal-Dominant Hypocalcemia Type 1: Prevalence in a Large Healthcare Population. American journal of human genetics 106, 734-747.

Ding, F., O'Donnell, J., Xu, Q., Kang, N., Goldman, N., and Nedergaard, M. (2016). Changes in the composition of brain interstitial ions control the sleep-wake cycle. Science 352 , 550-555.

Eigenbrod, O., Debus, K.Y., Reznick, J., Bennett, N.C., Sanchez-Carranza, O., Omerbasic, D., Hart, D.W., Barker, A.J., Zhong, W., Lutermann, H., et al. (2019). Rapid molecular evolution of pain insensitivity in multiple African rodents. Science 364, 852-859. 
Flourakis, M., Kula-Eversole, E., Hutchison, A.L., Han, T.H., Aranda, K., Moose, D.L., White, K.P., Dinner, A.R., Lear, B.C., Ren, D., et al. (2015). A Conserved Bicycle Model for Circadian Clock Control of Membrane Excitability. Cell 162, 836-848.

Ford, N.C., Ren, D., and Baccei, M.L. (2018). Nalcn Channels Enhance the Intrinsic Excitability of Spinal Projection Neurons. Pain.

Funato, H., Miyoshi, C., Fujiyama, T., Kanda, T., Sato, M., Wang, Z., Ma, J., Nakane, S., Tomita, J., Ikkyu, A., et al. (2016). Forward-genetics analysis of sleep in randomly mutagenized mice. Nature 539, 378-383.

Gama, L., and Breitwieser, G.E. (1998). A carboxyl-terminal domain controls the cooperativity for extracellular $\mathrm{Ca} 2+$ activation of the human calcium sensing receptor. A study with receptor-green fluorescent protein fusions. J Biol Chem 273, 29712-29718.

Hahn, S., Kim, S.W., Um, K.B., Kim, H.J., and Park, M.K. (2020). N-benzhydryl quinuclidine compounds are a potent and Src kinase-independent inhibitor of NALCN channels. Br J Pharmacol 177, 3795-3810.

Hebert, S.C., and Brown, E.M. (1996). The scent of an ion: calcium-sensing and its roles in health and disease. Current opinion in nephrology and hypertension 5, 45-53.

Heinemann, U., Konnerth, A., Pumain, R., and Wadman, W.J. (1986). Extracellular calcium and potassium concentration changes in chronic epileptic brain tissue. Adv Neurol 44, 641-661.

Heinemann, U., and Pumain, R. (1980). Extracellular calcium activity changes in cat sensorimotor cortex induced by iontophoretic application of aminoacids. Exp Brain Res 40, 247-250.

Herzog, R.I., Cummins, T.R., and Waxman, S.G. (2001). Persistent TTX-resistant Na+ current affects resting potential and response to depolarization in simulated spinal sensory neurons. J Neurophysiol 86, 1351-1364.

Hofer, A.M., and Brown, E.M. (2003). Extracellular calcium sensing and signalling. Nat Rev Mol Cell Biol 4, 530-538.

Humphrey, J.A., Hamming, K.S., Thacker, C.M., Scott, R.L., Sedensky, M.M., Snutch, T.P., Morgan, P.G., and Nash, H.A. (2007). A putative cation channel and its novel regulator: cross-species conservation of effects on general anesthesia. Curr Biol 17, 624-629.

Jospin, M., Watanabe, S., Joshi, D., Young, S., Hamming, K., Thacker, C., Snutch, T., Jorgensen, E., and Schuske, K. (2007). UNC-80 and the NCA ion channels contribute to endocytosis defects in synaptojanin mutants. Curr Biol 17, 1595-1600.

Kang, Y., Wu, J.-X., and Chen, L. (2020). Structure of voltage-modulated sodium-selective NALCN-FAM155A channel complex. bioRxiv doi: 10.1101/2020.07.26.221747. 
Kapoor, A., Satishchandra, P., Ratnapriya, R., Reddy, R., Kadandale, J., Shankar, S.K., and Anand, A. (2008). An idiopathic epilepsy syndrome linked to 3q13.3-q21 and missense mutations in the extracellular calcium sensing receptor gene. Ann Neurol 64, 158-167.

Kojima, S., Vignjevic, D., and Borisy, G.G. (2004). Improved silencing vector co-expressing GFP and small hairpin RNA. Biotechniques 36, 74-79.

Koroglu, C., Seven, M., and Tolun, A. (2013). Recessive truncating NALCN mutation in infantile neuroaxonal dystrophy with facial dysmorphism. Journal of medical genetics 50 , 515-520.

Krnjevic, K., Morris, M.E., and Reiffenstein, R.J. (1980). Changes in extracellular Ca2+ and $\mathrm{K}+$ activity accompanying hippocampal discharges. Can J Physiol Pharmacol 58, 579-582.

Kschonsak, M., Chua, H.C., Noland, C.L., Weidling, C., Clairfeuille, T., Bahlke, O.O., Ameen, A.O., Li, Z.R., Arthur, C.P., Ciferri, C., et al. (2020). Structure of the human sodium leak channel NALCN. Nature.

Lear, B.C., Darrah, E.J., Aldrich, B.T., Gebre, S., Scott, R.L., Nash, H.A., and Allada, R. (2013). UNC79 and UNC80, putative auxiliary subunits of the NARROW ABDOMEN ion channel, are indispensable for robust circadian locomotor rhythms in Drosophila. PLoS One 8, e78147.

Lee, J.H., Cribbs, L.L., and Perez-Reyes, E. (1999). Cloning of a novel four repeat protein related to voltage-gated sodium and calcium channels. FEBS Lett 445, 231-236.

Lee, S.Y., Vuong, T.A., Wen, X., Jeong, H.J., So, H.K., Kwon, I., Kang, J.S., and Cho, H. (2019). Methylation determines the extracellular calcium sensitivity of the leak channel NALCN in hippocampal dentate granule cells. Exp Mol Med 51, 1-14.

Lu, B., Su, Y., Das, S., Liu, J., Xia, J., and Ren, D. (2007). The neuronal NALCN channel contributes resting sodium permeability and is required for normal respiratory rhythm. Cell 129, 371-383.

Lu, B., Su, Y., Das, S., Wang, H., Wang, Y., Liu, J., and Ren, D. (2009). Peptide neurotransmitters activate a cation channel complex of NALCN and UNC-80. Nature 457, 741-744.

Lu, B., Zhang, Q., Wang, H., Wang, Y., Nakayama, M., and Ren, D. (2010). Extracellular calcium controls background current and neuronal excitability via an UNC79-UNC80-NALCN cation channel complex. Neuron 68, 488-499.

Lutas, A., Lahmann, C., Soumillon, M., and Yellen, G. (2016). The leak channel NALCN controls tonic firing and glycolytic sensitivity of substantia nigra pars reticulata neurons. eLife 5.

Morris, M.E., and Trippenbach, T. (1993). Changes in extracellular $[\mathrm{K}+]$ and $[\mathrm{Ca} 2+]$ induced 
by anoxia in neonatal rabbit medulla. Am J Physiol 264, R761-769.

Nicholson, C., Bruggencate, G.T., Steinberg, R., and Stockle, H. (1977). Calcium modulation in brain extracellular microenvironment demonstrated with ion-selective micropipette. Proc Natl Acad Sci U S A 74, 1287-1290.

Nilsson, P., Hillered, L., Olsson, Y., Sheardown, M.J., and Hansen, A.J. (1993). Regional changes in interstitial $\mathrm{K}+$ and $\mathrm{Ca} 2+$ levels following cortical compression contusion trauma in rats. J Cereb Blood Flow Metab 13, 183-192.

Owsianik, G., Talavera, K., Voets, T., and Nilius, B. (2006). Permeation and selectivity of TRP channels. Annu Rev Physiol 68, 685-717.

Philippart, F., and Khaliq, Z.M. (2018). Gi/o protein-coupled receptors in dopamine neurons inhibit the sodium leak channel NALCN. eLife 7.

Phillips, C.G., Harnett, M.T., Chen, W., and Smith, S.M. (2008). Calcium-sensing receptor activation depresses synaptic transmission. J Neurosci 28, 12062-12070.

Pidasheva, S., D'Souza-Li, L., Canaff, L., Cole, D.E., and Hendy, G.N. (2004). CASRdb: calcium-sensing receptor locus-specific database for mutations causing familial (benign) hypocalciuric hypercalcemia, neonatal severe hyperparathyroidism, and autosomal dominant hypocalcemia. Hum Mutat 24, 107-111.

Pierce-Shimomura, J.T., Chen, B.L., Mun, J.J., Ho, R., Sarkis, R., and McIntyre, S.L. (2008). Genetic analysis of crawling and swimming locomotry pattern in C. elegans. Proc Natl Acad Sci U S A 105, 20982-20987.

Priest, B.T., Murphy, B.A., Lindia, J.A., Diaz, C., Abbadie, C., Ritter, A.M., Liberator, P., Iyer, L.M., Kash, S.F., Kohler, M.G., et al. (2005). Contribution of the tetrodotoxin-resistant voltage-gated sodium channel NaV1.9 to sensory transmission and nociceptive behavior. Proc Natl Acad Sci U S A 102, 9382-9387.

Pumain, R., and Heinemann, U. (1985). Stimulus- and amino acid-induced calcium and potassium changes in rat neocortex. J Neurophysiol 53, 1-16.

Ray, K., Fan, G.F., Goldsmith, P.K., and Spiegel, A.M. (1997). The carboxyl terminus of the human calcium receptor. Requirements for cell-surface expression and signal transduction. J Biol Chem 272, 31355-31361.

Ren, D. (2011). Sodium leak channels in neuronal excitability and rhythmic behaviors. Neuron 72, 899-911.

Riccardi, D., and Kemp, P.J. (2012). The calcium-sensing receptor beyond extracellular calcium homeostasis: conception, development, adult physiology, and disease. Annu Rev Physiol 74, 271-297.

Ruat, M., Molliver, M.E., Snowman, A.M., and Snyder, S.H. (1995). Calcium sensing receptor: molecular cloning in rat and localization to nerve terminals. Proc Natl Acad Sci 
U S A 92, 3161-3165.

Shi, Y., Abe, C., Holloway, B.B., Shu, S., Kumar, N.N., Weaver, J.L., Sen, J., Perez-Reyes, E., Stornetta, R.L., Guyenet, P.G., et al. (2016). Nalcn Is a "Leak" Sodium Channel That Regulates Excitability of Brainstem Chemosensory Neurons and Breathing. J Neurosci 36, 8174-8187.

Silver, I.A., and Erecinska, M. (1990). Intracellular and extracellular changes of [Ca2+] in hypoxia and ischemia in rat brain in vivo. J Gen Physiol 95, 837-866.

Smith, S.M., Bergsman, J.B., Harata, N.C., Scheller, R.H., and Tsien, R.W. (2004).

Recordings from single neocortical nerve terminals reveal a nonselective cation channel activated by decreases in extracellular calcium. Neuron 41, 243-256.

Stray-Pedersen, A., Cobben, J.M., Prescott, T.E., Lee, S., Cang, C., Aranda, K., Ahmed, S., Alders, M., Gerstner, T., Aslaksen, K., et al. (2016). Biallelic Mutations in UNC80 Cause Persistent Hypotonia, Encephalopathy, Growth Retardation, and Severe Intellectual Disability. American journal of human genetics 98, 202-209.

Takenouchi, T., Inaba, M., Uehara, T., Takahashi, T., Kosaki, K., and Mizuno, S. (2018). Biallelic mutations in NALCN: Expanding the genotypic and phenotypic spectra of IHPRF1. American journal of medical genetics Part A 176, 431-437.

Vizard, T.N., O'Keeffe, G.W., Gutierrez, H., Kos, C.H., Riccardi, D., and Davies, A.M. (2008). Regulation of axonal and dendritic growth by the extracellular calcium-sensing receptor. Nat Neurosci 11, 285-291.

Vyleta, N.P., and Smith, S.M. (2011). Spontaneous glutamate release is independent of calcium influx and tonically activated by the calcium-sensing receptor. J Neurosci 31 , 4593-4606.

Wie, J., Bharthur, A., Wolfgang, M., Narayanan, V., Ramsey, K., Group, C.R.R., Aranda, K., Zhang, Q., Zhou, Y., and Ren, D. (2020). Intellectual disability-associated UNC80 mutations reveal inter-subunit interaction and dendritic function of the NALCN channel complex. Nat Commun 11, 3351.

Xie, J., Ke, M., Xu, L., Lin, S., Zhang, J., Yang, F.C., Wu, J., and Yan, Z. (2020). Structure of human sodium leak channel NALCN in complex with FAM155A. bioRxiv doi: 10.1101/2020.07.24.218958.

Xie, L., Gao, S., Alcaire, S.M., Aoyagi, K., Wang, Y., Griffin, J.K., Stagljar, I., Nagamatsu, S., and Zhen, M. (2013). NLF-1 delivers a sodium leak channel to regulate neuronal excitability and modulate rhythmic locomotion. Neuron 77, 1069-1082.

Xiong, Z., Lu, W., and MacDonald, J.F. (1997). Extracellular calcium sensed by a novel cation channel in hippocampal neurons. Proc Natl Acad Sci U S A 94, 7012-7017.

Yang, J., Ellinor, P.T., Sather, W.A., Zhang, J.F., and Tsien, R.W. (1993). Molecular 
determinants of $\mathrm{Ca} 2+$ selectivity and ion permeation in L-type Ca2+ channels. Nature 366, 158-161.

Yeh, E., Ng, S., Zhang, M., Bouhours, M., Wang, Y., Wang, M., Hung, W., Aoyagi, K., Melnik-Martinez, K., Li, M., et al. (2008). A putative cation channel, NCA-1, and a novel protein, UNC-80, transmit neuronal activity in C. elegans. PloS Biol 6, e55.

Yeh, S.Y., Huang, W.H., Wang, W., Ward, C.S., Chao, E.S., Wu, Z., Tang, B., Tang, J., Sun, J.J., Esther van der Heijden, M., et al. (2017). Respiratory Network Stability and Modulatory Response to Substance P Require Nalcn. Neuron 94, 294-303 e294.

Zhang, M., and Breitwieser, G.E. (2005). High affinity interaction with filamin A protects against calcium-sensing receptor degradation. J Biol Chem 280, 11140-11146.

Zhuang, X., Northup, J.K., and Ray, K. (2012). Large putative PEST-like sequence motif at the carboxyl tail of human calcium receptor directs lysosomal degradation and regulates cell surface receptor level. J Biol Chem 287, 4165-4176. 